\title{
Cloning, Tissue Expression Analysis, and Functional Characterization of Two 46 -Desaturase Variants of Sea Bass (Dicentrarchus labrax L.)
}

\author{
Santigosa, E. ${ }^{1}$; Geay, F. ${ }^{1}$; Tonon, T. ${ }^{2,3}$, Le Delliou, H. ${ }^{1}$, Kuhl, H. ${ }^{4}$, Reinhardt, R. ${ }^{4}$, Corcos, L. ${ }^{5,6}$, \\ Cahu, C. ${ }^{1}$, Zambonino-Infante, J.L. ${ }^{1}$, Mazurais, D. ${ }^{1, *}$
}

1 Ifremer Marine Fish Nutrition Team, Nutrition Aquaculture and Genomics Research Unit, UMR 1067, Ifremer, Technopole Brest-Iroise, BP 70, 29280 Plouzané, France

2 UPMC Univ Paris 6, UMR 7139 Végétaux marins et Biomolécules, LIA DIAMS, Station Biologique, F 29682, Roscoff, France

3 CNRS, UMR 7139 Végétaux marins et Biomolécules, LIA DIAMS, Station Biologique, F 29682,

Roscoff, France

4 Max-Planck-Institute Molecular Genetics, Ihnestr. 63-73, 14195 Berlin-Dahlem, Germany.

5 Université de Brest, INSERM, U613, ECLA, Brest F-29200, France

6 Université Européenne de Bretagne, Faculté de Médecine, Brest F-29200, France

*: Corresponding author: D. Mazurais, Tel.: +33 2982244 87; Fax: +332 98224366
E-mail address: dmazurai@ifremer.fr

\begin{abstract}
:
Fish are the main source of the n-3 highly unsaturated fatty acids, which are crucial for human health. Their synthesis from $\mathrm{C}_{18}$ precursors is mediated by desaturases and elongases, but the activity of these enzymes has not been conclusively established in marine fish species. This study reports the cloning, tissue expression, and functional characterization of a sea bass (Dicentrarchus labrax L.) $\Delta 6$ desaturase and one of its splicing variants. Two cDNAs with open reading frames of 1,346 and 1,354 bp were cloned and named D6D and D6D-V, respectively. Both deduced protein sequences (445 and 387 amino acids, respectively) contained two transmembrane regions and the $\mathrm{N}$-terminal cytochrome b5 domain with the HPGG motif characteristic of microsomal desaturases. D6D presents three histidine-rich regions, whereas in D6D-V, an insertion of eight nucleotides in the boundaries of exons 10 and 11 modified the third histidine-rich domain and led to insertion of a premature STOP codon, resulting in a shorter predicted protein. Quantitative real-time polymerase chain reaction assay of gene expression showed that D6D was highly expressed in the brain and intestine, and to a lesser extent, in muscle and liver; meanwhile, D6D-V was expressed in all tissues tested, but at level at least 200-fold lower than D6D. Functional analysis in yeast showed that sea bass D6D encodes a fully functional $\Delta 6$-desaturase with no residual $\Delta 5$-desaturase activity. This desaturase does not exhibit a clear preference for $n-3$ versus $n-6 C_{18}$ substrates. Interestingly, D6D-V is a nonfunctional protein, suggesting that the $\mathrm{C}$-terminal end is indispensable for protein activity.
\end{abstract}

Keywords: Sea bass (Dicentrarchus labrax) - Desaturase - HUFA biosynthesis - Fish - EPA 


\section{Introduction}

The decrease in worldwide fisheries recorded in the last years (Tidwell and Allan, 2001; Pauly et al., 2005 ; Brunner et al., 2009), in conjunction with aquaculture expansion (FAO, 2006), leads to the utilization of vegetable oils rich in $C_{18}$ PUFA in aquafeeds (Bell and Waagbø, 2008). However, the capacity of marine fish species to bioconvert the vegetable $\mathrm{C}_{18}$ precursors linoleic (LN; 18:2n-6) and linolenic (LNA; 18:3n-3) acids into long-chain highly unsaturated fatty acids (HUFA; chain length $\geq \mathrm{C} 20$ with $\geq 3$ double bonds) eicosapentaneoic (EPA; 20:5n-3), docosahexaneoic (DHA; 22:6n-3) and arachidonic (AA; 20:4n-6) acids is controversial. In freshwater species such as Atlantic salmon (Salmo salar) or rainbow trout (Oncorhynchus mykiss), the desaturation/elongation pathway is under nutritional regulation. Thus, when these fish species are fed a diet lacking fish oil, they are capable of modulating the activity of the enzymes to produce the long-chain HUFAs (Tocher et al., 2006, Zheng et al, 2005). In contrast, mostmarine fish species, when deprived of long-chain HUFAs, are not capable of completing the desaturation/elongation steps that allow the synthesis of EPA, DHA and AA and, consequently, they have a dietary requirement for long-chain HUFA. In this regard, the low level of EPA and DHA biosynthesis from $\mathrm{C}_{18}$ vegetable precursors in sea bream hepatocytes has been related to a low $\Delta 5$-desaturase activity (Tocher and Ghioni, 1999), whereas in the turbot TF cell line, the HUFA elongation/desaturation pathway seems to be impaired in the $C_{18}$ to $C_{20}$ elongation step (Ghioni et al., 1999). In the particular case of sea bass (Dicentrarchus labrax L.), the flesh fatty acid profile is impoverished in long chain n3 and n- 6 fatty acids when fish are fed vegetable-oil diets (Mourente et al., 2005b; Mourente and Bell, 2006), with a concomitant decrease of nutritional value. However, previous studies have proved that this fish species possess the desaturase/elongase activities necessary to produce EPA, AA and DHA from $\mathrm{C}_{18}$ fatty acids (Mourente and Dick, 2002; Mourente et al., 2005a), even if the conversion rates are extremely low. In this context, it is important to better characterise the different enzymes (elongases and desaturases) involved in HUFA synthesis pathway in order to improve the use of vegetable oils lacking long chain HUFA for marine fish aquafeeds.

Fatty acid desaturases introduce double bounds in selected positions of the acyl chains (Cook, 1996). Particularly, $\Delta 6$-desaturases are the first enzymes involved in the biosynthesis of long-chain HUFA from the $\mathrm{C}_{18} \mathrm{n}-3$ and $\mathrm{n}-6$ precursors. Over the last few years, some desaturases have been isolated and characterized from different fish species (supplementary data 1). Thus, full length cDNAs encoding $\Delta 6$-desaturases from rainbow trout (Oncorhynchus mykiss), sea bream (Sparus aurata), Atlantic salmon (Salmo salar), cherry salmon (Oncorhynchus masou), carp (Cyprinus carpio), turbot (Scopththalmus maximus), nile tilapia (Oreochromis niloticus), cod (Gadus morhua) and cobia (Rachycentron canadum) are now available. In addition, $\Delta 5$-desaturases from Atlantic salmon and cherry salmon, as well as a zebrafish (Danio rerio) desaturase with both $\Delta 5 / \Delta 6$ activities, have been characterized (Hastings et al., 2001). These enzymes contain three histidine boxes, up to three hydrophobic domains, and a N-terminal cytochrome $b_{5}$-like domain (Shanklin et al., 1994). A high percentage of identity (around $90 \%$ ) between the $\Delta 5$ - and $\Delta 6$-desaturase cDNAs of the same species have been reported (Zheng et al, 2005).

To get deeper insight into the desaturation capacity of sea bass (Dicentrarchus labrax L.), the objective of this study was to clone the $\Delta 6$-desaturase, to survey its expression profile in different tissues, and finally to functionally characterize this enzyme in order to elucidate its role in the HUFA synthesis pathway of this fish species.

\section{Materials and Methods}

2.1. Cloning of putative fatty acyl desaturase from sea bass. 
Total RNA was extracted from sea bass larvae (Day 45 post hatching) fed with a fishmeal/fish-oil diet using the TRIzol ${ }^{\circ}$ reagent (Invitrogen, Ltd., USA). Five micrograms of RNA were reverse-transcribed using iScript cDNA Synthesis Kit (Bio-Rad Laboratories, Hercules, $\mathrm{CA}$ ) primed by the oligonucleotide Reverse 0 (Table 1). Available fish desaturase sequences (supplementary data 1 ) were aligned to design a degenerate Forward 1 primer (Table 1). Reverse 1 primer was designed after alignment of sequences contained in sea bass partial clones obtained from multi-tissue cDNA libraries described in sigenae databases (cdn22p0006m07, cdnp0002m05 and cdn24p0001j11; http://publiccontigbrowser.sigenae.org:9090). These primers were used for PCR amplification in a TC512 instrument (Techne, UK) under the following conditions: initial denaturation $10 \mathrm{~min}$ at $94^{\circ} \mathrm{C}, 37$ cycles of $1 \mathrm{~min}$ denaturation at $94^{\circ} \mathrm{C}, 45 \mathrm{~s}$ annealing at $55^{\circ} \mathrm{C}$ and $1 \mathrm{~min} 30 \mathrm{~s}$ at $72^{\circ} \mathrm{C}$ for elongation, and a final extension at $72^{\circ} \mathrm{C}$ for $10 \mathrm{~min}$. A nested PCR was then performed using Forward 2 and Reverse 2 primers (Table 1) to improve amplification specificity. The expected fragment was then purified, cloned into the pCRTM II-TOPO plasmid and used for transformation of ONE ShotTM competent cells (Invitrogen). The fragment was sequenced and found to contain $845 \mathrm{bp}$.

From this sequence, the specific primers 5'RACE1, 5'RACE2 and 5'RACE3 (Table 1) were designed and used to obtain the 5'-UTR region with the 5'/3'RACE kit (Roche, USA) following the manufacturer's instructions. After cloning and sequencing the isolated DNA as described above, the 5'-UTR specific primer Forward 3 (Table 1) was designed. This primer was combined with the 3'-UTR Reverse 3 primer, designed according to sequences contained in sea bass available clones, to obtain the full length ORF by using the Advantage ${ }^{\circledR}$ cDNA Polymerase Mix (Clontech Laboratories, Inc., USA) under the following conditions: $10 \mathrm{~min}$ at $94^{\circ} \mathrm{C}, 40$ cycles of 1 min denaturation at $94^{\circ} \mathrm{C}, 45 \mathrm{~s}$ annealing at $62^{\circ} \mathrm{C}$ and $1 \mathrm{~min} 45 \mathrm{~s}$ at $72^{\circ} \mathrm{C}$ for elongation, and a final extension at $72^{\circ} \mathrm{C}$ for $10 \mathrm{~min}$. Cloning and sequencing of the PCR products revealed the presence of two highly homologous cDNAs that were named sea bass-D6D and sea bass-D6D-V respectively. All PCR and RACE products were sequenced by Millegen (France).

For comparative analyses, the deduced amino acid sequences of $\Delta 6$-desaturases from various species were aligned using ClustalX, and sequence phylogenies were predicted using the Neighbor Joining method (Saitou and Nei, 1987).

\subsection{Sea bass tissue RNA extraction, and quantitative real time PCR (qrt-PCR).}

Nine tissues (brain, pyloric caeca, anterior intestine, posterior intestine, muscle, liver, kidney, heart and skin) of two adult fish fed with a commercial fish-meal/fish-oil diet were isolated and total RNA extraction was immediately performed using TRIzol ${ }^{\circledR}$ reagent. Twelve micrograms of total RNA were reverse-transcribed into cDNA by using the QuantiTect Reverse Transcription Kit (QIAGEN, Germany). Expression of both sea bass-D6D and sea bass-D6D-V was studied by qrt-PCR using specific primers (Table 1). PCR product sizes for sea bass-D6D and D6D-V were 138 and 150 bp respectively. Amplification from cDNA samples was performed using $\mathrm{iQ}^{\mathrm{TM}} \mathrm{SYBR}^{\circledR}$ Green Supermix (Bio-Rad Laboratories, Hercules, CA) under the following conditions: 1 min $30 \mathrm{~s}$ of initial denaturation at $95^{\circ} \mathrm{C}, 45$ cycles of $30 \mathrm{~s}$ at $95^{\circ} \mathrm{C}$ and $1 \mathrm{~min}$ at $65^{\circ} \mathrm{C}$. This was followed by product melt to confirm single PCR products. EF1 was used as a housekeeping gene for normalization of mRNA levels. Thermal cycling and fluorescence detection were conducted in a MyiQ Single Color RealTime PCR Detection System (Bio-Rad).

\subsection{Heterologous expression of sea bass desaturases cDNA in yeast}

Forward 3 and Reverse 3 primers (Table 1 ) were used for the amplification of the ORFs of each desaturase transcript (D6D and D6D-V) from cDNA template synthesised from larvae total RNA. PCR products were cloned into the pYES2.1 TOPO expression plasmid (Invitrogen) to obtain the recombinant plasmids pYESD6D and pYESD6D-V, which were then used to transform TOP10F' $E$. coli (Invitrogen). After sequence confirmation, $S$. 
cerevisiae strain INVSc1 (Invitrogen) was transformed with one of the recombinant plasmids according to the pYES2.1TOPO ${ }^{\circ}$ TA Expression Kit manufacturers instructions. Yeast transformed with the empty pYES2.1 plasmid was used as control. Transformants containing pYES2.1, pYESD6D or pYESD6D-V were selected on solid minimal medium plates lacking uracil.

For functional expression, cultures were grown at $25^{\circ} \mathrm{C}$ in minimal medium containing $0.67 \%$ $(\mathrm{w} / \mathrm{v})$ nitrogen base, $0.19 \%(\mathrm{w} / \mathrm{v})$ dropout medium, and $2 \%$ raffinose $(\mathrm{w} / \mathrm{v})$. Expression of the transgene was induced at an $O_{600}$ of 0.2 by supplementing with galactose to $2 \%(\mathrm{w} / \mathrm{v})$ and tergitol to $1 \%(\mathrm{w} / \mathrm{v})$ final concentration. At that time, the appropriate fatty acids were added as follows (final concentration): $0.5 \mathrm{mM}$ of $18: 3 \mathrm{n}-3,0.5 \mathrm{mM}$ of $18: 2 \mathrm{n}-6$, or $1 \mathrm{mM}$ of $20: 4 \mathrm{n}-3$ (Eicosatetraenoic acid, ETA). Incubation was carried out at $25^{\circ} \mathrm{C}$ for 3 days in a shaking incubator.

\subsection{Fatty acid analysis}

Yeast cells were harvested by centrifugation (10,000 g, $15 \mathrm{~min})$. Total lipid extraction was performed according to Folch et al. (1957) with dichloromethane replacing chloroform. Briefly, cells were homogenised in $2 \mathrm{~mL}$ of 2:1 dichloromethane:methanol ( $/ \mathrm{v})$ containing $0.01 \%$ butylated hydroxytoluene (BHT). Cell debris were discarded by centrifugation $(14,000$ g, $10 \mathrm{~min}, 4^{\circ} \mathrm{C}$ ). Eight hundred $\mu \mathrm{L}$ of $\mathrm{NaCl} 0.75 \%$ were added to the supernatant and samples were decanted for $1 \mathrm{~h}$ at RT. Then, the bottom phase was transferred into a microcentrifugation tube for saponification $\left(90^{\circ} \mathrm{C}, 3 \mathrm{~min}\right)$ using $0.5 \mathrm{~mL} 2 \mathrm{M} \mathrm{KOH}$-methanol. Two $\mathrm{mL}$ of hexane were added, and after centrifugation $(630 \mathrm{~g}, 10 \mathrm{~min}$ ) the supernatant was recovered and the hexane evaporated. Five hundred microliters of $6 \mathrm{~N} \mathrm{HCl}$ and $2 \mathrm{~mL}$ of hexane were added, and after centrifugation (630 g, $10 \mathrm{~min}$ ) the supernatant was recovered and evaporated. To prepare fatty acid methyl esters (FAME), $1 \mathrm{~mL} \mathrm{HCl} 2.5 \%$ in $\mathrm{MeOH}$ was added $\left(90^{\circ} \mathrm{C}, 3 \mathrm{~min}\right)$, and after addition of $1 \mathrm{~mL}$ double distillate water and of $2 \mathrm{~mL}$ hexane, samples were centrifuged (630 $\mathrm{g}, 10 \mathrm{~min})$ and the supernatant was recovered, evaporated and diluted in $0.5 \mathrm{~mL}$ of hexane. FAME were separated by GLC (Clarus500 Perkin-Elmer with a flame ionisation detector, BPX 70 capillary column: $30 \mathrm{~m} \times 0.22 \mathrm{~mm}$ i.d. $\times 0.25 \mu \mathrm{m}$ film thickness). The percentage of conversion (conversion rate) of each FA substrate was calculated as follows: $100 \times$ (Product area /(Substrate area + Product area).

\section{Results}

\subsection{Cloning of putative fatty acyl desaturase from sea bass}

Starting from partial cDNA sequences obtained from several clones of a multi-tissue library, the sequence of a putative desaturase transcript was completed by 5' and 3'RACE. This allowed us to identify two transcripts of 1346 and 1354 nucleotides respectively, named sea bass-D6D (GenBank accession no. EU647692) and sea bass-D6D-V (GenBank accession no. EU439924). The alignment of the two cDNA sequences (Fig. 1) revealed an insertion of 8 nucleotides at the boundaries of exon 10 and exon 11 in the D6D-V cDNA, which interrupted the amino acid translation just after exon 10, and gave a deduced amino acid sequence of 387 aa rather than 445 aa for D6D. The alignment of the $\triangle 6$-desaturase cDNA and the genomic sequences (obtained by 454 sequencing of the D. labrax BAC clone bassbac102L2) revealed 12 exons spanning $7158 \mathrm{bp}$ of genomic DNA as illustrated in figure 1 . All splice sites except the donor site of intron 5 (GC..AG) exhibit the consensus splice site GT..AG. The cDNA aligned completely to the genomic DNA and resulted in only 1 nucleotide mismatch in the 3'UTR at position 59 (A in CDNA, G in gDNA; data not shown).

The comparison of the sea bass D6D deduced amino acid sequences with zebrafish, mouse and human $\Delta 6$-desaturase (Fig. 2) revealed an identity of 68,64 and $65 \%$, respectively. In addition, two transmembrane domains, the typical desaturase $\mathrm{N}$-terminal cytochrome b5-like domain (HPGG), as well as the three characteristic membrane-bound histidine motifs 
(HDxGH, HFQHH and QIEHH), were well conserved in sea bass D6D transcript. In the alternative splicing transcript (D6D-V), the third histidine motif was replaced by the QIEHQ sequence (Fig. 2). A pair-wise comparison between fish and human desaturase sequences ((supplementary data 2)) showed that sea bass amino acid sequences exhibit identity ranging from 82 to $94 \%$ with marine fish, while values were lower with sequences isolated from salmonids (around 76\%) and zebrafish (68\%). In addition, about half of the residues were identical between the sea bass and the human desaturases. Phylogenetic analysis comparing both sea bass sequences with characterized and putative $\Delta 5$ and $\Delta 6$-desaturases identified in fish showed that sea bass D6D and D6D-V sequences cluster with cobia, sea bream and turbot sequences rather than with salmonids, carp and zebrafish desaturases (Fig. 3).

\section{2. $D 6 D$ and $D 6 D-V$ gene expression in several sea bass tissues}

D6D and D6D-V expression in sea bass tissues (brain, liver, pyloric caeca, anterior intestine, posterior intestine, muscle, kidney, heart and skin) was monitored by quantitative PCR analysis (Fig 4.). Results show that D6D was mainly expressed in brain and intestine, followed by muscle and liver, while its expression was weak in the other tissues considered for the analysis. Sea bass D6D-V expression was maximal in the anterior intestine, followed by posterior intestine, brain and pyloric caeca. Interestingly, the absolute Ct values recorded for D6D (ranging from 19 to 22) in comparison to those obtained for D6D-V (between 28 and 30) showed that the splicing variant was expressed at a level at least 200 -fold lower than D6D (data not shown).

\subsection{Heterologous expression of sea bass desaturase cDNA in yeast}

To complete our analysis we functionally characterised both newly identified sea bass desaturases by heterologous expression in S. cerevisiae (Table 2). Their activity and specificity was assessed by feeding recombinant yeast expressing pYESD6D or pYESD6D-V with potential $\Delta 6(18: 2 n-6$ and $18: 3 n-3)$ and $\Delta 5(20: 4 n-3)$ desaturase substrates. The fatty acid composition of the yeast transformed with the control vector (pYES2.1) showed the presence of the main fatty acids currently found in the yeast host $(16: 0,16: 1 \mathrm{n}-7,18: 0$ and 18:1n-9), together with the exogenously fed fatty acids (see fatty acids profiles in supplementary data 3). In experiments with the pYESD6D-transformed yeast, additional peaks were observed when $18: 3 n-3$ and $18: 2 n-6$ were added to the culture medium. These new fatty acids, Stearidonic acid (STD) 18:4n-3 and Gamma-linolenic acid (GLA) 18:3n-6 respectively, were identified by gas chromatography (GC) analysis after comparison with the profiles obtained in presence of pure standards (data not shown). The percentage of conversion ranged from 7.4 to 10.4 for the LNA and from 5.7 to 8.2 for the LN according to the different replicates of the feeding experiments (Table 2). This observation suggested that the sea bass D6D exhibits no significant preference between C18 n-6 and n-3 PUFA. Concerning yeast transformed with the pYESD6D-V plasmid, the percentage of conversion was nil for LNA and LN. No EPA was found when ETA $(20: 4 n-3)$ was added in the induction medium in presence of any constructs.

\section{Discussion}

Data presented in this work represent the first information on cloning, tissue distribution, and functional characterisation of a sea bass desaturase. This is an important step in the understanding of the molecular basis of marine fish HUFA synthesis

The D6D sea bass cDNA ORF encoded for a 445 amino acid protein with high similarity to fish fatty acyl desaturases, being more similar to sea bream (Seiliez et al., 2003), turbot 
(Zheng et al., 2004) and cobia (Zheng et al., 2009) than to salmonid sequences, as revealed by amino acid pair-wise comparison and phylogenetic analysis. The functional characterization of the protein in yeast confirmed the sea bass enzyme as a $\Delta 6$-desaturase, with no preference for either the omega-3 substrate 18:3n-3 or the omega- 6 linoleate. Similar observations have been done after the functional characterisation of mammalian, fungal and moss desaturases (Aki et al., 1999; Cho et al., 1999; Kajikawa et al., 2004; Kaewsuwan et al., 2006), with the exception of the plant family Primula sp. $\Delta 6$-desaturase and the Mantoniella squamata $\Delta 6$-desaturase that preferentially desature the $n-3$ substrates (Hoffmann et al., 2008; Sayanova et al., 2003). In contrast, the selectivity for $n-3$ rather than for $n-6$ substrates is clear for the zebrafish bifunctional $\Delta 5 / \Delta 6$-desaturase (Hastings et al., 2001), as well as for other fish $\Delta 6$-desaturases (Oncorhynchus mykiss, Sparus aurata, Cyprinus carpio and Psetta maximus; Zheng. et al., 2004). Whilst differences in yeast uptake have been described when studying fatty acids of different carbon length (De Antueno et al., 2001), no preference should exist in the uptake when comparing fatty acids with the same chain length.

The percentage of conversion of $18: 3 n-3$ to $18: 4 n-3$ measured for the sea bass D6D ranged from 7.4 to 10.4 for the LNA and from 5.7 to 8.2 for the LN. This poor desaturation capacity could explain, at least partially, sea bass impairment in the bioconversion of the $\mathrm{C}_{18}$ fatty acids provided by vegetable oil-based diets (Mourente et al., 2005a).

Some of the fish $\Delta 6$-desaturases characterized so far presented a low capacity to desaturate the $\Delta 5$ substrates $20: 4 n-3$ and 20:3n-6, with conversion rates from $0.2 \%$ in rainbow trout (Zheng et al., 2004), sea bream (Zheng et al., 2004) or turbot (Zheng et al., 2004) to $2.3 \%$ in Atlantic salmon (Zheng et al., 2005) or cobia (Zheng et al., 2009). In our report, no $\Delta 5$ activity was detected in transgenic yeasts containing the D6D sea bass desaturase genes when cultivated in presence of 20:4n-3, indicating that, like Atlantic cod (Tocher et al., 2006), the sea bass $\Delta 6$-desaturase protein was not capable of desaturate $20: 4 n-3$ at the $\Delta 5$ position, or that this activity was extremely low and thus was not detectable under the conditions tested.

Results obtained in this work, in conjunction with the existing literature concerning the controversial HUFA synthesis efficiency in marine fish species (Sargent et al., 2002), and especially in sea bass (Mourente and Dick, 2002; Mourente et al., 2005a), allow us to hypothesise on the occurrence of $\Delta 5$-desaturase activity. Firstly, the low activity detected for sea bass liver (Mourente et al., 2005a) could be related to an unknown gene encoding for a $\Delta 5$-desaturase, and thus responsible for the trace amounts of EPA (20:5n-3) and AA (20:4n6 ) detected in hepatocyte cultures in the presence of $C_{18}$ precursors (Mourente et al., 2005a). The existence of an enzyme with $\Delta 5$-desaturation capacity is supported by the fact that different desaturases with distinct $\Delta 6$ and $\Delta 5$ specificities have been reported for freshwater species (Hastings et al., 2005), even if the origin of the two independent desaturase genes is unclear (Zheng 2004; Napier et al. 2003). However, the low capacity of marine fish species to synthesize long chain HUFA from $\mathrm{C}_{18}$ precursors could also be related to an absence of the $\Delta 5$-desaturase gene. In this regard, to the best of our knowledge, no marine fish $\Delta 5$ desaturase proteins have been reported. Moreover, preliminary analysis of the results from 'shot gun' genome sequencing suggests the existence of a unique desaturase gene in sea bass (data not shown). If this is the real situation, it is possible to hypothesize that the zebrafish bifunctional desaturase might have evolved in a unifunctional $\Delta 6$-desaturase by changes in catalytic residues which would have abolished the $\Delta 5$ activity in marine fish species. The difference in evolution of desaturase activities in freshwater and marine fish could be related to the fact that marine fish natural diet is rich in EPA and DHA while freshwater fish diet is usually poor in long chain HUFA. Therefore, the freshwater species need to cover their requirements by the desaturation and elongation of $\mathrm{C}_{18}$ precursors (Sargent et al., 1995, 1999).

Recent studies in sea bass HUFA pathway have shown the occurrence of numerous splicing variants for the D6D gene. Thus, in addition to the D6D-V detected in the present work (GenBank accession no. EU439924), five other variants exist in the NCBI database (GenBank accession no. AM746707, AM746706, AM746705, AM746704, AM746703). Despite the high homology between the two sequences identified in this study, the D6D-V 
splicing variant indicated that the C-terminal end was indispensable for the activity of the protein. In addition, even if the physiological occurrence of these splicing variants was doubtful because of the lower expression levels of the variant when compared to the main desaturase transcript, the qrt-PCR analysis performed in our study demonstrated that the D6D-V variant was expressed in several tissues from juvenile sea bass (brain, intestine, muscle, liver, kidney, heart and skin). Concerning its role in regulation of $\Delta 6$-desaturase activity, it is possible that the D6D-V, like the other identified variants, could decrease substrate availability by trapping it into the enzyme active site that would be preserved in the variant proteins. This would then diminish the apparent activity of the main protein. The strong expression of the D6D gene in brain is in concordance with previous results obtained for Atlantic cod (Tocher et al., 2006) and cobia (Zheng et al., 2009). In addition, the higher level of transcripts detected in intestine when compared to liver is in agreement with the level of enzymatic activity monitored in vitro by Mourente et al. (2005a), who have measured a stronger desaturation rates in enterocytes than in hepatocytes. Further studies will be needed to more fully address the correlation between D6D expression levels with desaturation capacity in different sea bass organs.

In summary, we reported here the first characterisation of the sea bass $\Delta 6$-desaturase, and showed its high level of expression in the brain and intestine. This work also demonstrates the existence of a predicted 387 amino acid non-functional splicing variant expressed in a wide range of sea bass tissues. The functional $\Delta 6$-desaturase did not exhibit substrate selectivity towards $n-3$ and $n-6 C_{18}$ substrates, and no $\Delta 5$-desaturase residual activity was detected by yeast heterologous expression. The low conversion rate determined for sea bass $\Delta 6$-desaturase could, at least partially, explain the low HUFA biosynthesis when this species is fed vegetable-based diets. The discovery of this limited step in the HUFA synthesis process for sea bass may enable to manipulate and optimise the activity of the pathway to allow efficient and effective use of vegetable oils in aquaculture.

In fact, whilst the sea bass $\Delta 6$-desaturase cDNA sequence has a strong homology with those of other fish species exhibiting better conversion rates, it is not excluded that the dysfunction of the enzyme can be due to mutation at the level of the nucleotide sequence. Accordingly, the use of transgenic fish to commercial ends not being accepted by consumers at the present time, it is however possible to consider the selection of sea bass family exhibiting better rates of delta6-desaturase activity as soon as delta- 6 desaturase gene polymorphism will be determined. In addition, regarding other potential limiting steps in sea bass HUFA synthesis pathway such as bioconversion of ETA into EPA, other oil resources rich in HUFA such as microalgae may be considered in aquafeeds. 


\section{References}

Aki, T., Shimada, Y., Inagaki, K., Higashimoto, H. , Kawamoto, S., Shiget, S. , Ono, K. and Suzuki, O. (1999). Molecular cloning and functional characterisation of rat $\Delta 6$ fatty acid desaturase. Biochem Biophys Res Commun 255: 575-579.

Bell, J.G., and Waagbø, R. (2008). Safe and nutritious aquaculture produce: benefits and risks of alternative sustainable aquafeeds. In: Holmer, M., Black, K.D., Duarte, C.M., Marba, N., Karakassis, I. (Eds.); Aquaculture in the Ecosystem. Springer Verlag, Netherlands, pp. 185-225.

Brunner, E.J., Jones, P.J., Friel, S., and Bartley, M. (2009). Fish, human health and marine ecosystem health: policies in collision. Int J Epidemiol 38: 93-100.

Cho, H.P., Nakamura, M.T., and Clarke, S.D. (1999). Cloning, expression and nutritional regulation of the human $\Delta 6$-desaturase. J Biol Chem 274: 471-477.

Cook, H.W. (1996). Fatty acid desaturation and chain elongation in eukaryote In: D.E. Vance and J.E. Vance (Eds), Biochemistry of Lipids, Lipoproteins and Membranes vol. 129, Elsevier, Amsterdam, pp. 152.

De Antueno, R.J., Knickle, L.C., Smith, H., Elliot, M.L., Allen, S.J., Nwaka, S., and Winther, M.D. (2001). Activity of human D5 and D6 desaturases on multiple n-3 and n-6 polyunsaturated fatty acids. FEBS Lett 509: 77-80

Folch, J., Lees, M., and Sloane-Stanley, G.H. (1957). A simple method for the isolation and purification of total lipids from animal tissues. J Biol Chem 226: 497-509.

Food And Agricultural Organisation (FAO), 2006. State of world aquaculture 2008. Fao Fisheries Technical Paper No. 500. FAO, Rome, 134 pp.

Ghioni, C., Tocher, D.R., Bell, M.V., Dick, J.R. and Sargent, J.R. (1999). Low $C_{18}$ to $C_{20}$ fatty acid elongase activity and limited conversion of stearidonic acid, $18: 4 n-3$, to eicosapentaenoic acid, 20:5n-3, in a cell line from the turbot, Scophthalmus maximus. Biochim Biophys Acta 1437: 170-181.

Hastings, N., Agaba, M., Tocher, D. R., Leaver, M.J., Dick, J.R., Sargent, J.R., and Teale, A.J. (2001). A vertebrate fatty acid desaturase with $\Delta 5$ and $\Delta 6$ activities. Proc Natl Acad Sci U S A 98: 14304-14309.

Hastings, N., Agaba, M.K., Tocher, D.R., Zheng, X., Dickson, C.A., Dick, J.R., and Teale, A.J. (2005). Molecular cloning and functional characterization of fatty acyl desaturase and elongase cDNAs involved in the production of eicosapentaenoic

and docosahexaenoic acids from a-linolenic acid in Atlantic salmon (Salmo salar). Mar Biotechnol 6: 463-474.

Hoffmann, M., Wagner, M., Abbadi, A., Fulda, M., and Feussner, I. (2008). Metabolic engineering of 3-very long chain polyunsaturated fatty acid production by an exclusively acyl-CoA-dependent pathway. J Biol Chem 283: 22352-22362.

Kaewsuwan, S., Cahoon, E. B., Perroud, P-F., Wiwat, C., Panvisavas, N., Quatrano, R. S., Cove, D.J. and Bunyapraphatsara, N. (2006). Identification and functional characterization of the moss Physcomitrella patens $\Delta 5$-desaturase gene involved in arachidonic and eicosapentaenoic acid biosynthesis. J Biol Chem 281: 21988-21997. 
Kajikawa, M. Yamato, K. T., Kohzu, Y., Nojiri, M., Sakuradani, E., Shimizu, S., Sakai, Y., Fukuzawa, H., and Ohyama, K. (2004). Isolation and characterization of D6-desaturase, an ELO-like enzyme and D5-desaturase from the Liverwort Marchantia Polymorpha and production of arachidonic and eicosapentaenoic acids in the methylotrophic yeast Pichia Pastoris. Plant Molec Biol 54: 335-352.

Mourente, G., Dick, J. R., Bell, J. G., and Tocher, D. R. (2005a). Effect of partial substitution of dietary fish oil by vegetable oils on desaturation and beta-oxidation of [1-C-14]18:3n-3 (LNA) and [1-C-14]20:5n-3 (EPA) in hepatocytes and enterocytes of European sea bass (Dicentrarchus labrax L.). Aquaculture 248: 173-186.

Mourente, G., Good, J.E. and Bell, J.G. (2005b). Partial substitution of fish oil with rapeseed, linseed and olive oils in diets for European sea bass (Dicentrarchus labrax L.) effects on flesh fatty acid composition, plasma prostaglandins $E_{2}$ and $F_{2 \alpha}$, immune function and effectiveness of a fish oil finishing diet. Aquac Nutr 11: 25-40.

Mourente, G., and Bell, J.G. (2006). Partial replacement of dietary fish oil with blends of vegetable oils (rapeseed, linseed and palm oils) in diets for European sea bass (Dicentrarchus labrax L.) over a long term growth study: Effects on muscle and liver fatty acid composition and effectiveness of a fish oil finishing diet. Comp Biochem Physiol B 145: 389399.

Mourente, G., and Dick, J.R. (2002). Influence of partial substitution of dietary fish oil by vegetable oils on the metabolism of [1-C14]18:3n-3 in isolated hepatocytes of European sea bass (Dicentrarchus labrax L.). Fish Physiol Biochem 26: 297-308.

Napier, J.A., Michaelson, L.V. and Sayanova, O. (2003). The role of cytochrome b5 fusion desaturases in the synthesis of polyunsaturated fatty acids. Prost Leukot Essent Fatty Acids 68: 135-143.

Pauly, D., Watson, R., and Alder, J. (2005). Global trends in world fisheries: impacts on marine ecosystems and food security. Philos Trans R Soc Lond B Biol Sci 360: 5-12.

Saitou, N., and Nei, M., (1987). The neighbor-joining method. A new method for reconstructing phylogenetic trees. Mol Biol Evol 4: 406-425.

Sargent, J.R., Bell, J.R.,Bell, M.V., Henderson, R.J., and Tocher, D.R. (1995). Requirement criteria for essential fatty acids. J Appl Ichthyol 11: 183-198.

Sargent, J.R. , Bell, J.G., McEvoy, L., Tocher, D.R., and Estevez, A. (1999). Recent developments in the essential fatty acid nutrition of fish. Aquaculture 177: 191-199.

Sargent, J.R., Tocher, D.R., and Bell J.G. (2002). The lipids. In: J.E. Halver and R.W. Hardy, Editors, Fish Nutrition (3rd ed.), Academic Press, USA, pp. 181-257.

Sayanova, O.V., Beaudoin, F., Michaelson, L.V., Shewry, P.R., and Napier, J.A. (2003). Identification of Primula fatty acid $\Delta 6$-desaturases with n-3 substrate preferences. FEBS Lett 542:100-104.

Seiliez, I., Panserat, S., Corraze, G., Kaushik, S., and Bergot, P. (2003). Cloning and nutritional regulation of a $\Delta 6$-desaturase-like enzyme in the marine teleost gilthead sea bream (Sparus aurata). Comp Biochem Physiol B 135: 449-460. 
Shanklin, J., Whittle, E. and Fox, B. G. (1994). Eight histidine residues are catalytically essential in a membrane-associated iron enzyme,stearoyl-CoA desaturase, and are conserved in alkane hydroxylase and xylene monooxygenase. Biochemistry 33: 12787 12794.

Tidwell, J. H., and Allan, G. L. (2001). Fish as food: aquaculture's contribution. Ecological and economic impacts and contributions of fish farming and capture fisheries. Embo Reports 2: 958-963.

Tocher, D.R. and Ghioni, C. (1999). Fatty acid metabolism in marine fish: low activity of $\Delta 5$ desaturation in gilthead sea bream (Sparus aurata) cells. Lipids 34: 433-440.

Tocher, D., Zheng, X., Schlechtriem, C., Hastings, N., Dick, J., and Teale, A. (2006). Highly unsaturated fatty acid synthesis in marine fish: Cloning, functional characterization, and nutritional regulation of fatty acyl $\Delta 6$-desaturase of Atlantic cod (Gadus morhua L.). Lipids 41: 1003-1016.

Zheng, X., Seiliez, I., Hastings, N., Tocher, D.R., Panserat, S., Dickson, C.A., Bergot, P., and Teale, A.J. (2004). Characterization and comparison of fatty acyl $\Delta 6$-desaturase cDNAs from freshwater and marine teleost fish species. Comp Biochem Physiol B 139: 269-279.

Zheng, X., Tocher, D.R., Dickson, C.A., Dick, J.R., Bell, J.G., and Teale, A.J. (2005). Highly unsaturated fatty acid synthesis in vertebrates: New insights with the cloning and characterization of a $\Delta 6$-desaturase of Atlantic salmon. Lipids 40: 13-24.

Zheng, X., King, Z., Xu, Y., Monroig, O., Morais, S. and Tocher, D.R. (2009). Physiological roles of fatty acyl desaturases and elongases in marine fish: Characterisation of cDNAs of fatty acyl $\Delta 6$-desaturase and elovl5 elongase of cobia (Rachycentron canadum). Aquaculture 290: 122-131.

\section{Aknowledgements}

This work was partially supported by Marine Genomique Europe, by Axe1 « Génomique et Chimie Bleue »- Europôle Mer. and by IFR 148 SclnBioS. The authors thank Erick Desmarais for his technical assistance in gene sequence treatment. E Santigosa was supported by a postdoctoral fellowship from the Fundación Alfonso Martin Escudero (Spain).

\section{Figures}

Figure 1

Fig. 1. Exon/Intron boundaries of sea bass D6D and D6D-V gene (exon1-12). Location of different exons is shown by alternation of white/grey areas. 5' and 3' extremities of intronic sequences are indicated in lower case letters. Hash in the boundaries of exon5/exon6 denotes a non consensus splice donor and the size of each intron is indicated between brackets. Asterisks correspond to the nucleotides conserved between the two sea bass cDNA sequences. Predicted amino acid translation noted in the boundaries of exon10/exon11 shows the stop in the translation of the D6D-V cDNA. 


$$
\begin{aligned}
& \begin{array}{l}
\text { Sea bass-D6D } \\
\text { Sea bass-D6D-V }
\end{array} \\
& \begin{array}{l}
\text { Sea bass-D60 } \\
\text { Sea bass-D60-V }
\end{array} \\
& \begin{array}{l}
\text { Sea bass-D60 } \\
\text { Sea bass- }-060-V
\end{array} \\
& \begin{array}{l}
\text { Sea bass- } 060 \\
\text { Sea bass- } 060-V
\end{array} \\
& \begin{array}{l}
\text { Sea bass- } D 60 \\
\text { Sea bass }-060-V
\end{array} \\
& \begin{array}{l}
\text { Sea bass- }-060 \\
\text { Sea bass- }-060-V
\end{array} \\
& \begin{array}{l}
\text { Sea bass-D60 } \\
\text { Sea bass-D60-V }
\end{array} \\
& \begin{array}{l}
\text { Sea bass-D60 } \\
\text { Sea bass- } 060-V
\end{array} \\
& \begin{array}{l}
\text { Sea bass- } 060 \\
\text { Sea bass } D 60-V
\end{array} \\
& \begin{array}{l}
\text { Sea bass- } 060 \\
\text { Sea bass }-060-v
\end{array} \\
& \begin{array}{l}
\text { Sea bass- } 060 \\
\text { Sea bass }-060-v
\end{array} \\
& \begin{array}{l}
\text { Sea bass- } 060 \\
\text { Sea bass }-060-y
\end{array}
\end{aligned}
$$

E1
ATGGGAGGTGGAGGCCAACTGACGGAGCAGGAGGTCGGCAGCAGGCGAGCTGGAGGT 60
ATGGAGGTGAGGCAACTGACGGAGCCAGGAGAGTGGGCAGCAGGGAGCTGGAGGT $6 \theta$ GTTTACACCTGGGAGGAGGTGCAGAGCCACTGCAACAGGATTGACCAGTGGCTGGTCATT 120

m.

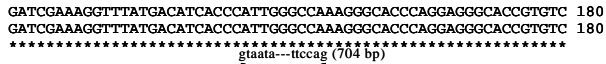

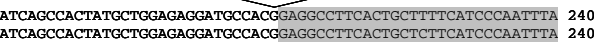

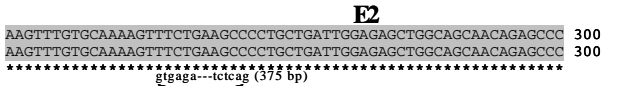

AGCCAGGACCGAAACAAAATGCAGCAATTATACAGGATTTCTACACTTTACGTGCGCAG 36

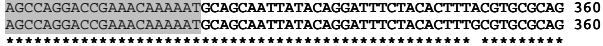

GCAGAGAGCGAGGGTCTGTTTAAAGCTCAGCCTTTGTTCTTCTGCCTCCACCTGGGTCAC 420 GCAGAGAGCGAGGTCTGTTTAAAGCTCAGCCTTTGTTCTTCTGCCTCCACCTGGGTCAC 420 ATCCTGCTGTTGGAGGCCCTCGCCTGGCTCA 3
3 TCATCTGGCTCTGGGAACCAGCTGGACT 480 ATCTGCTGTTGGAGGCCTCGCCTGGCTCATCATCTGGCTCTGGGGAACAGCTGGACT 480 CTGACATTTTTGTGCTCGATCATGCTGGCAACTGCTCAGTCGCAGGCCGGATGGCTGCAG 540 CTGACATTTTGTGCTCGATCATGCTGGCAACTGCTCAGTCGAGGCGGATGGCTGCAG 54 EA CACGACTTTGGCCACCTGTCTGTCTTCAAGAAGTCAGCTGGAATCACATGTTGCACAAG 600
CACGACTTGGCCACCTGTCTGTCTTCAAGAGTCCAGCTGGATCACATGTTGCACAAG 600

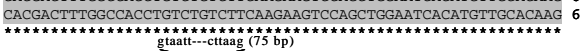
TTTGTCATCGGTCATCTAAAGGGGCCTCTGCCAACTGGTGGAATCATCGGCATTTCCAG 660 TCTGTCATCGGTATCAAAGGGAGCTCTCGCCAACTGGTGGAATAATCGCATTCCAG 660 CATCACGCTAAACCCAACATCTTCAGTAAGGACCCAGATGTCAACATGTTGCACATCTTC 720 CATCACGCTAAACCCAACATCTTCAGTAGGACCCAGATGTCGACATGTTGCACATCTTC 720
Sea bass-D60
Sea bass-D6D-v

Sea bass-D60
Sea bass-000- $v$

Sea bass- -060
sea bass-060- $v$

Sea bass- -060
Sea bass-060-V

Sea bass- -060
Sea bass-060- $\mathrm{V}$

Sea bass-D6D
Sea bass-060- $-\mathrm{V}$

Sea bass-D6D

Sea bass $-D 60$
Sea bass- $D 60-V$

Sea bass-060
Sea bass $-060-v$

Sea bass-D60

Sea bass- -060
Sea bass- $060-\mathrm{V}-\mathrm{V}$

Sea bass-D6D
Sea bass-D6D- $\mathrm{V}$ gc\#aag---tacag (110 bp)

E6

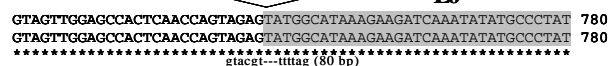

CATCACCAACACCAGTACTTCCTTCTTGTTGGACCACCGCTGCTCATTCCAGTTTACTTC 840
CATCACCAACACCAGTACTTCCTTCTTGTTGGACCACCGCTGCTCATTCCAGTTACTTC 840

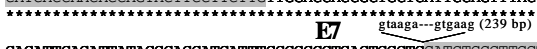
CACATTCAGATTATACGCACCATGATTTCCCGCCGTGACTGGGTGGATCTGGCTTGGTTT 990 * ATGTCTTACTACCTTCGCTACCTGTGCTGTTATGTACCCTTGTATGGCCTGTTTGGCTCG 960
ATTCTACTACTTCGCTACCTGTGCTGTIATGACCCTGGTAGGCTGTTGGGCTCG 960

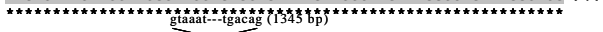
TTGGCGCTCATCAGTTTCGTCAGGTTTTTGGAGAGTCACTGGTTTGTGTGGGTGACTCAG 1020 TTGGGGCTCATCAGTTTCGTCAGGTTTTGGAGAGTCACTGGTTTGTGTGGGTGACTCAG 1020 ATGAATCATCTGCCGATGGACATCGACCACGAGAGCACCATGACTGGCTGACCATGCAG 1080

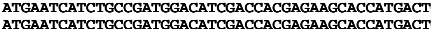
***************************************************t* E10
TTACAAGCCACCTGTAATATTGAGAAGTCTCTTCAACGACTGGTTCAGCGGACACCTC $\mathbf{1 1 4 0}$
TTACAAGCCACCTGTATACTGAGAAGTCCTCTTCAACGACTGGTCAGCGACACCTC 1140

$$
\text { gtaagt---tctag (1622 bp) }
$$

AACTTTCAATCGAACACCA-......-TTTGTTTCCTACAATGCCGCGCCACAACTACC 1192
AACTTTCAAATCGACACCAGTAAGTCATTGGTTCCTACAATGCCGCGCCACAACTACC 1200 H Q Stop V I C

\section{E11}

ACCTGGTGGCGCCGCTGGTCCATGCACTGTGTGAGAAACATGGGATTCCTTACCAGGTGA 1252

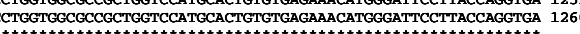

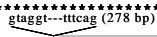

AGACGATGTGGCAAGGCCTTGTTGATGTTATCAGGTCACTGAAAAACTCAGGGGACCTCT 1312

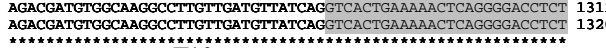
E12

GGCTTGATGCATATCTCCATAAATGA 1338
GGCTTGATGCATATCTCCATAATGA 1346

\section{Figure 2}

Fig. 2. Alignment of the deduced amino acid sequences from sea bass D6D and D6D-V with desaturases from zebrafish (GenBank accession No.Q9DEX7), mouse (GenBank accession No.NP062673) and human (GenBank accession No.NP004256). The cytochrome b5-domain is dot-underlined. Putative transmembrane domains are shown in shaded areas, and three histidine-rich regions are boxed. The asterisks indicate the heme-binding motif (HPGG), and two highly conserved histidine positions, are in bold. 
Mouse-D6D

Human-D6D

Sea bass-D6D

Sea bass-D6D-V

Zebrafish-D5/6D

Mouse-D6D

Human-D6D

Sea bass-D6D

Sea bass-D6D-V

Zebrafish-D5/6D

Mouse-D6D

Human - D6D

Sea bass-D6D

Sea bass-D6D-V

Zebrafish-D5/6D

Mouse-D6D

Human-D6D

Sea bass-D6D

Sea bass-D6D-V

Zebrafish-D5/6D

Mouse-D6D

Human-D6D

Sea bass-D6D

Sea bass-D6D-V

Zebrafish-D5/6D

Mouse-D6D

Human-D6D

Sea bass-D6D

Sea bass-D6D-V

Zebrafish-D5/6D

Mouse-D6D

Human-D6D

Sea bass-D6D

Sea bass-D6D-V

Zebrafish-D5/6D

Mouse-D6D

Human-D6D

Sea bass-D6D

Sea bass-D6D-V

Zebrafish-D5/6D
MGKGGNQGEGSTERQAPMP - TFRWEEIQKHNLRTDRWLVIDRKVYNVTKWSQRHPGGHRV 59 MGKGGNQGEGAAEREVSVP - TFSWEEIQKHNLRTDRWLVIDRKVYNITKWSIQHPGGQRV 59 MGGGGQLTEPGESGSRRAGGVYTWEEVQSHCNRNDQWLVIDRKVYDITHWAKGHPGGHRV 60 MGGGGQLTEPGESGSRRAGGVYTWEEVQSHCNRNDQWLVIDRKVYDITHWAKGHPGGHRV 60 MGGGGQQTDRITDTNGRFS-SYTWEEVQKHTKHGDQWVVVERKVYNVSQWVKRHPGGLRI 59

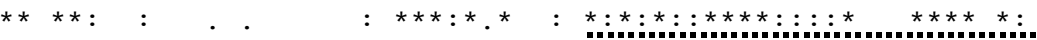

IGHYSGEDATDAFRAFHLDLDFVGKFLKPLLIGELAPEEPSLDRGKSSOITEDFRALKKT 119 IGHYAGEDATDAFRAFHPDLEFVGKFLKPLLIGELAPEEPSQDHGKNSKITEDFRALRKT 119 ISHYAGEDATEAFTAFHPNLKFVQKFLKPLLXGELAATEPSQDRNKNAAIIQDFYTLRAQ 120 ISHYAGEDATEAFTALHPNLKFVQKFLKPLLIGELAATEPSQDRNKNAAIIQDFYTLRAQ 120 LGHYAGEDATEAFTAFHPNLQLVRKYLKPLLIGELEASEPSQDRQKNAALVEDFRALRER 119

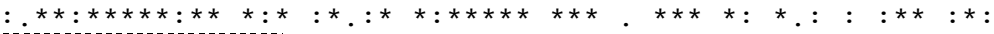

AEDMNLFKTNHLFFFLLLSHIIVMESLAWFILSYFGTGWIPTLVTAFVLATSQAQAGWLQ 179 AEDMNLFKTNHVFFLLLLAHIIALESIAWFTVFYFGNGWIPTLITAFVLATSQAQAGWLQ 179 AESEGLFKAQPLFFCLHLGHILLLEALAWLIIWXWGTSWTLTFLCSIMLATAQSQAGWLQ 180 AESEGLFKAQPLFFCLHLGHILLLEALAWLIIWLWGTSWTLTFLCSIMLATAQSQAGWLQ 180 LEAEGCFKTQPLFFALHLGHILLLEAIAFMMVWYFGTGWINTLIVAVILATAQSQAGWLQ 179

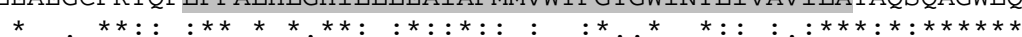

HDYGH SVYKKSIWNHVVHKFVIGHLKGASANWWNHR HFQHHAKPNIFHKDPDIKSLHVF 239 HDYGH SVYRKPKWNHLVHKFVIGHLKGASANWWNHR HFQHHAKPNIFHKDPDVNMLHVF 239 HDFGH SVFKKSSWNHMLHKFVIGHLKGASANWWNHR HFQHHAKPNIFSKDPDVNMLHIF 240 HDFGH SVFKKSSWNHMLHKSVIGHLKGASANWWNHRHFQHHAKPNIFSKDPDVDMLHIF 240 HDFGH SVFKTSGMNHLVHKFVIGHLKGASAGWWNHRHFQHHAKPNIFKKDPDVNMLNAF 239

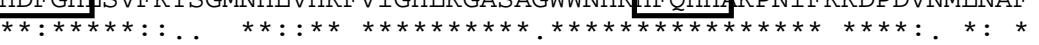

VLGEWQPLEYGKKKLKYLPYNHQHEYFFLIGPPLLIPMYFQYQIIMTMISRRDWVDLAWA 299 VLGEWQPIEYGKKKLKYLPYNHQHEYFFLIGPPLLIPMYFQYQI IMTMIVHKNWVDLAWA 299 VVGATQPVEYGIKKIKYMPYHHQHQYFLLVGPPLLIPVYFHIQIIRTMISRRDWVDLAWS 300 VVGATQPVEYGIKKIKYMPYHHQHQYFLLVGPPLLIPVYFHIQIIRTMISRRDWVDLAWS $30 \odot$ VVGNVQPVEYGVKKIKHLPYNHQHKYFFFIGPPLLIPVYFOFOIFHNMISHGMWVDLLWC 299

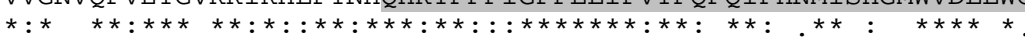

ISYYMRFFYTYIPFYGILGALVFLNFIRFLESHWFVWVTQMNHLVMEIDLDHYRDWFSSQ 359 VSYYIRFFITYIPFYGILGALLFLNFIRFLESHWFVWVTQMNHIVMEIDQEAYRDWFSSQ 359 MSYYLRYLCCYVPLYGLFGSLALISFVRFLESHWFVWVTOMNHLPMDIDHEKHHDWLTMO 360 MSYYLRYLCCYVPLYGLFGSLALISFVRFLESHWFVWVTQMNHLPMDIDHEKHHDWLTMQ 360 ISYYVRYFLCYTQFYGVFWAIILFNFVRFMESHWFVWVTQMSHIPMNIDYEKNQDWLSMQ 359

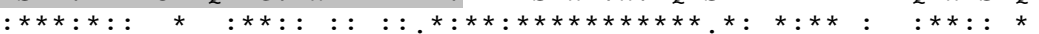

LAATCNVEOSFFNDWFSGHLNFQIEHHFPTMPRHNLHKIAPLVKSLCAKHGIEYOEKPL 419 LTATCNVEQSFFNDWFSGHLNFQIEHHUFPTMPRHNLHKIAPLVKSLCAKHGIEYQEKPL 419 LQATCNIEKSSFNDWFSGHLNFQIEHHUFPTMPRHNYHLVAPLVHALCEKHGIPYQVKTM 420 LQATCNTEKSSFNDWFSGHLNFQIEHQ LVATCNIEQSAFNDWFSGHLNFQIEHH丩FPTVPRHNYWRAAPRVRALCEKYGVKYQEKTL 419

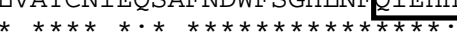

LRALIDIVSSLKKSGELWLDAYLHK 444

LRALLDIIRSLKKSGKLWLDAYLHK 444 WQGLVDVIRSLKNSGDLWLDAYLHK 445

YGAFADIIRSLEKSGELWLDAYLNK 444 
Figure 3

Fig. 3. Phylogeny of desaturase deduced amino acid sequences. The tree was constructed by the neighbor-joining method (Saitou and Nei, 1987) using CLUSTALX and NJPLOT. The horizontal branch length is proportional to the amino acid substitution rate per site. The numbers represent the frequencies with which the tree topology presented here was replicated after 1000 bootstrap iterations. Arrows highlight the location of sea bass delta- 6 desaturase variants. Asterisks denote desaturase sequences that have not been functionally characterized.

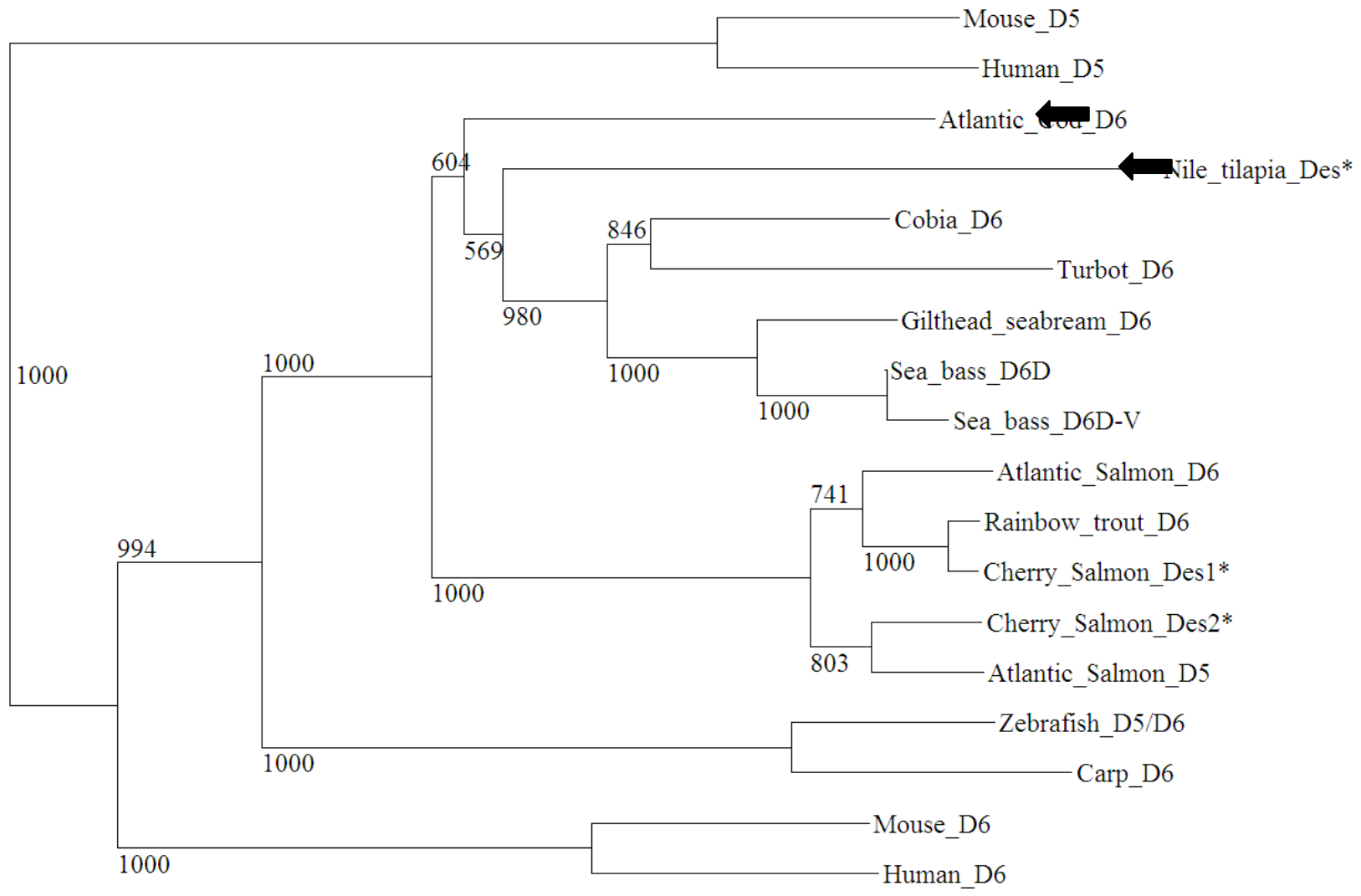


Figure 4

Fig. 4. Sea bass D6D (A) and D6D-V (B) gene expression in several tissues. Levels of relative D6D or D6D-V expression were determined by qRT-PCR and after normalisation by the expression of EF-1 housekeeping gene.
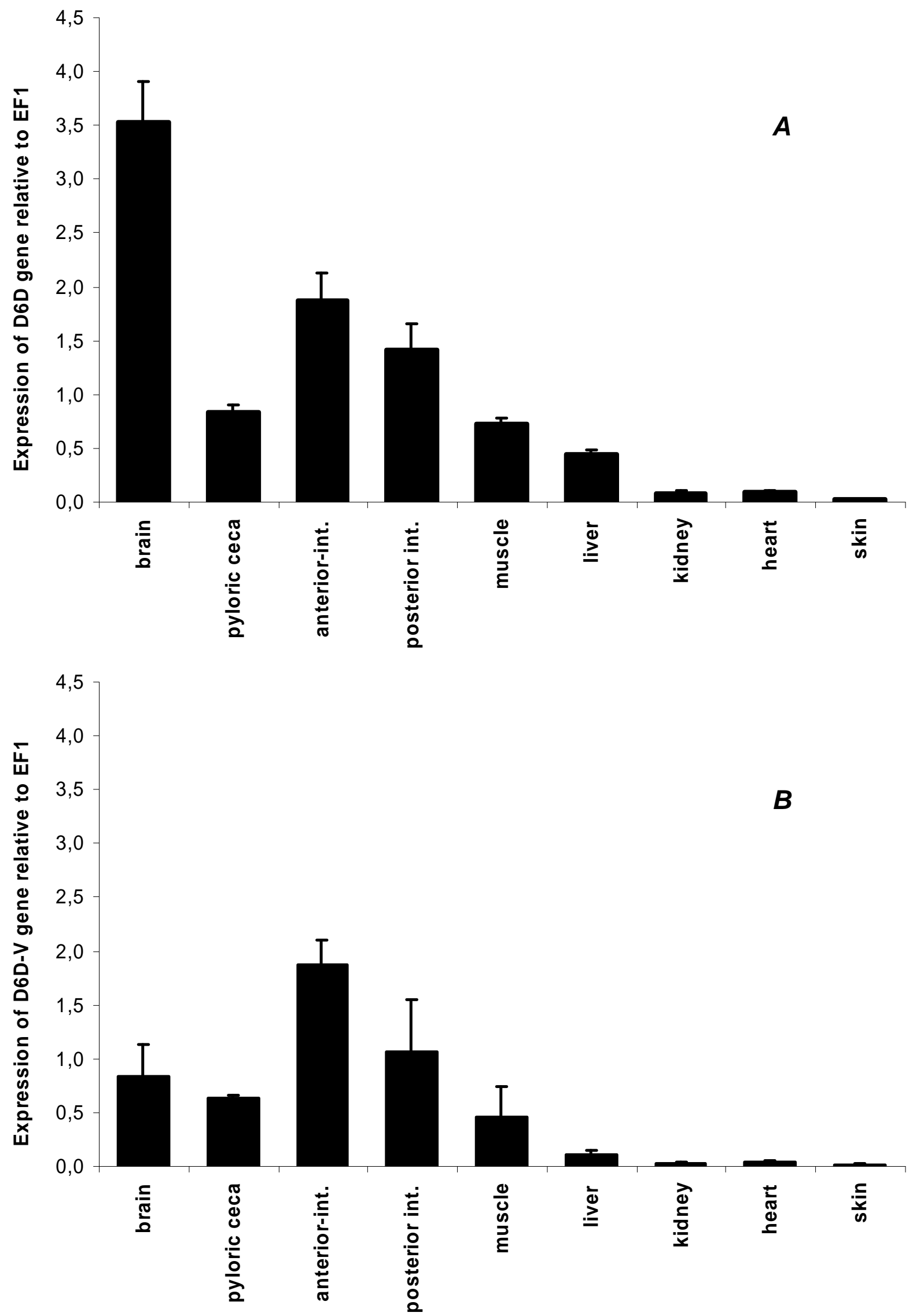
Tables

Table 1. Primers used in this study.

\begin{tabular}{|c|c|}
\hline Use & Primer (5'-3') \\
\hline \multicolumn{2}{|c|}{ Partial cDNA cloning } \\
\hline & Reverse 0: ACCCACACAAACCAGTGACTCT ${ }^{a}$ \\
\hline & Forward 1: ATGGGKGGCGGAGGHCAGCAGA ${ }^{b}$ \\
\hline & Reverse 2: ACCAGTGACTCTCCAAAAATYT ${ }^{a}$ \\
\hline & Forward 2: KGGCGGAGGHCAGCAGA ${ }^{b}$ \\
\hline & Reverse 2: TGTGGAAGTAAACTGGAATGAG ${ }^{a}$ \\
\hline \multicolumn{2}{|c|}{ 5' UTR cloning } \\
\hline & 5'RACE1: CCTTTCGATCAATGACCAGCC ${ }^{\mathrm{c}}$ \\
\hline & 5'RACE2: CATTCCTGTTGCAGTGGCTC ${ }^{\mathrm{C}}$ \\
\hline & 5'RACE3: CGCCTGCTGCCCGACTCTCC ${ }^{c}$ \\
\hline \multicolumn{2}{|c|}{ Full-length cDNA cloning } \\
\hline & Forward 3: TTTAGTGTAGGCTTCAGGTGG ${ }^{\mathrm{C}}$ \\
\hline & Reverse 3: GGTACAGGGTAGAGAATACRATTGG ${ }^{b}$ \\
\hline \multicolumn{2}{|c|}{ qrt-PCR } \\
\hline & D6D-F: CATCGACCACGAGAAGCACC ${ }^{\mathrm{C}}$ \\
\hline & D6D-R: GGCATTGTAGGAAACAAATGGTG ${ }^{\mathrm{c}}$ \\
\hline & D6D-V-F: GATGGACATCGACCACGAGAA ${ }^{\mathrm{c}}$ \\
\hline & D6D-V-R: CATTGTAGGAAACAAATGACTTAC ${ }^{c}$ \\
\hline
\end{tabular}

${ }^{a}$ Specific sea bass primers designed from database clones.

${ }^{\mathrm{b}}$ Degenerate primers designed from available fish desaturases.

${ }^{\mathrm{c}}$ Specific sea bass primers designed from sequences identified in this study. 
Table 2. Percentage of LN (18:3n-3), LNA (18:2n-6) and ETA (20:4n-3) conversion into STD (18:4n-3), GLA (18:3n-6) and EPA (20:5n-3) as measured after analysis by Gas Chromatography of fatty acid contents in yeast transfected by different clones. pYES2Empty: Expression vector pYES2 without any insert. pYESD6D: Expression vector pYES2 including D6D cDNA. pYESD6D-V: Expression vector pYES2 including D6D-V cDNA. ND= Not Detectable. Each feeding experiment being performed in triplicate, this table represents results of a representative experiment.

\begin{tabular}{|c|c|c|c|}
\hline Clone tested & $\begin{array}{c}\text { Substrate FA fed, } \\
\% \text { found }\end{array}$ & $\begin{array}{c}\text { Product FA, } \\
\% \text { found }\end{array}$ & Conversion, \% \\
\hline pYES2-Empty & $18: 3 n-3,46.78 \%$ & $18: 4 n-3, N D$ & ND \\
\hline pYES2-Empty & $18: 2 n-6,48,53 \%$ & $18: 3 n-6, N D$ & ND \\
\hline pYES2-Empty & $20: 4 n-3,12.34 \%$ & $20: 5 n-3, N D$ & ND \\
\hline pYESD6D & $18: 3 n-3,51.37 \%$ & $18: 4 n-3,6.01 \%$ & $10.4 \%$ \\
\hline pYESD6D & $18: 2 n-6,45.51 \%$ & $18: 3 n-6,4.05 \%$ & $8.17 \%$ \\
\hline pYESD6D & $20: 4 n-3,9.28 \%$ & $20: 5 n-3, N D$ & ND \\
\hline pYESD6D-V & $18: 3 n-3,64.9 \%$ & $18: 4 n-3, N D$ & ND \\
\hline pYESD6D-V & $18: 2 n-6,50.7 \%$ & $18: 3 n-6, N D$ & ND \\
\hline pYESD6D-V & $20: 4 n-3,12.42 \%$ & $20: 5 n-3, N D$ & ND \\
\hline
\end{tabular}


Supplementary data 1. Available fish fatty acyl desaturase sequences and GenBank Accession Numbers. An asterisk denotes a desaturase sequence that has not been functionally characterized. The percentage of conversion (conversion rate) of each FA substrate was calculated as follows: 100 x (Product area /(Substrate area + Product area).

\begin{tabular}{|c|c|c|c|c|c|c|c|c|}
\hline \multirow[t]{2}{*}{ Species } & \multirow[t]{2}{*}{ Type } & \multirow{2}{*}{$\begin{array}{c}\text { GenBank } \\
\text { Accession No }\end{array}$} & \multirow[t]{2}{*}{ Authors submission } & \multicolumn{4}{|c|}{ conversion rate } & \multirow[t]{2}{*}{ Functional Characterization } \\
\hline & & & & $18: 3 n-3$ & $20: 3 n-6$ & $18: 2 n-6$ & $20: 4 n-3$ & \\
\hline $\begin{array}{l}\text { Rainbow trout } \\
\text { (Oncorhynchus mykiss) }\end{array}$ & $\Delta 6$ & AF30191 & Seiliez et al, 2001 & 31.5 & ND & 3.6 & 0.2 & Seiliez et al, 2001 \\
\hline $\begin{array}{l}\text { sea bream } \\
\text { (Sparus aurata) }\end{array}$ & $\Delta 6$ & AY055749 & Seiliez et al, 2003 & 23.1 & 0.1 & 12.2 & 0.2 & Seiliez et al, 2003 \\
\hline $\begin{array}{l}\text { Atlantic salmon } \\
\text { (Salmo salar) }\end{array}$ & $\Delta 6$ & AY458652 & Zheng et al, 2005 & 60.1 & ND & 14.4 & 2.3 & Zheng et al, 2005 \\
\hline $\begin{array}{l}\text { Cherry salmon } \\
\text { (Oncorhynchus masou) }\end{array}$ & $\Delta 6^{*}$ & AB070444 & $\begin{array}{l}\text { Yoshizaki et al. } \\
\text { (unpublished) }\end{array}$ & - & - & - & - & $\begin{array}{l}\text { Yoshizaki et al. } \\
\text { (unpublished) }\end{array}$ \\
\hline $\begin{array}{l}\text { Carp } \\
\text { (Cyprinus carpio) }\end{array}$ & $\Delta 6$ & AF309557 & Hastings et al., 2001 & 7.0 & 0.4 & 1.5 & 0.5 & Hastings et al., 2001 \\
\hline $\begin{array}{l}\text { Turbot } \\
\text { (Scopththalmus maximus) }\end{array}$ & $\Delta 6$ & AY546094 & Zheng et al, 2004 & 59.5 & ND & 31.2 & 0.1 & Zheng et al, 2004 \\
\hline $\begin{array}{l}\text { nile tilapia } \\
\text { (Oreochromis niloticus) }\end{array}$ & $\Delta 6^{*}$ & AB069727 & $\begin{array}{l}\text { Sirisuay et al. } \\
\text { (unpublished) }\end{array}$ & - & - & - & - & $\begin{array}{l}\text { Sirisuay et al. } \\
\text { (unpublished) }\end{array}$ \\
\hline $\begin{array}{l}\text { Cod } \\
\text { (Gadus morhua) }\end{array}$ & $\Delta 6$ & DQ054840 & Tocher et al, 2006 & 33.5 & ND & 17.5 & ND & Tocher et al, 2006 \\
\hline $\begin{array}{l}\text { Cobia } \\
\text { (Rachycentron canadum) }\end{array}$ & $\Delta 6$ & FJ440238 & Zheng et al., 2009 & 50.8 & 0.2 & 36.5 & 2.4 & Zheng et al., 2009 \\
\hline $\begin{array}{l}\text { Atlantic salmon } \\
\text { (Salmo salar) }\end{array}$ & $\Delta 5$ & AF478472 & Hastings et al, 2005 & 0.6 & 0.9 & 0.4 & 10.2 & Hastings et al, 2005 \\
\hline $\begin{array}{l}\text { Cherry salmon } \\
\text { (Oncorhynchus masou) }\end{array}$ & $\Delta 5^{\star}$ & EU098126 & $\begin{array}{c}\text { Yoshizaki and Shusa } \\
\text { (unpublished) }\end{array}$ & - & - & - & - & $\begin{array}{l}\text { Yoshizaki and Shusa } \\
\text { (unpublished) }\end{array}$ \\
\hline $\begin{array}{l}\text { Zebrafish } \\
\text { (Danio rerio) }\end{array}$ & $\Delta 5 / \Delta 6$ & AF309556 & Hastings et al., 2001 & 29.4 & 8.3 & 11.7 & 20.4 & Hastings et al., 2001 \\
\hline $\begin{array}{l}\text { Sea bass } \\
\text { (Dicentrarchus labrax) }\end{array}$ & $\Delta 6$ & EU647692 & $\begin{array}{c}\text { Terova et al., } 2008 \\
\text { (unpublished) }\end{array}$ & 10.4 & ND & 8.2 & ND & Santigosa et al., 2009 \\
\hline $\begin{array}{l}\text { Sea bass } \\
\text { (Dicentrarchus labrax) }\end{array}$ & $\Delta 6$ & EU439924 & $\begin{array}{l}\text { Geay et al., } 2008 \\
\text { (unpublished) }\end{array}$ & ND & ND & ND & ND & Santigosa et al., 2009 \\
\hline
\end{tabular}


1 Supplentary data 2. Identity matrix showing results of a pair-wise comparison between the amino acid sequences of fish and human

2 fatty acyl desaturases. Percentages of identity and similarity (values between brackets) are given.

\begin{tabular}{|c|c|c|c|c|c|c|c|c|c|c|c|c|}
\hline & $\begin{array}{c}\text { Gilthead } \\
\text { sea bream }\end{array}$ & Turbot & Cobia & $\begin{array}{l}\text { Atlantic } \\
\text { Cod }\end{array}$ & $\begin{array}{l}\text { Rainbow trout } \\
\text { D6D }\end{array}$ & $\begin{array}{c}\text { Atlantic } \\
\text { Salmon D5D }\end{array}$ & $\begin{array}{c}\text { Atlantic } \\
\text { salmon D6D }\end{array}$ & $\begin{array}{c}\text { Cherry } \\
\text { salmon D5D }\end{array}$ & $\begin{array}{l}\text { Cherry } \\
\text { salmon } \\
\text { D6D }\end{array}$ & $\begin{array}{l}\text { Zebrafish } \\
\text { D5D/D6D }\end{array}$ & $\begin{array}{l}\text { Human } \\
\text { D6D }\end{array}$ & $\begin{array}{l}\text { Human } \\
\text { D5D }\end{array}$ \\
\hline Sea bass D6D & $94.4(98.0)$ & \begin{tabular}{|c|}
83.4 \\
$(91.9)$ \\
\end{tabular} & \begin{tabular}{|c|}
87.9 \\
$(92.6)$
\end{tabular} & $\begin{array}{c}81.7 \\
(88.8)\end{array}$ & $\begin{array}{c}76.4 \\
(87.0)\end{array}$ & $\begin{array}{c}76.4 \\
(86.6)\end{array}$ & $\begin{array}{c}76.7 \\
(86.6)\end{array}$ & $\begin{array}{c}76.8 \\
(86.7)\end{array}$ & $\begin{array}{c}76.9 \\
(87.2)\end{array}$ & $\begin{array}{c}68.3 \\
(82.2)\end{array}$ & $\begin{array}{c}65.3 \\
(78.2)\end{array}$ & $\begin{array}{c}51.8 \\
(64.5)\end{array}$ \\
\hline Gilthead sea bream & & \begin{tabular}{|c|}
84.0 \\
$(92.1)$
\end{tabular} & $\begin{array}{l}86.7 \\
(93.0)\end{array}$ & $\begin{array}{c}81.9 \\
(88.1)\end{array}$ & $\begin{array}{c}76.4 \\
(86.8)\end{array}$ & $\begin{array}{c}76.9 \\
(86.6)\end{array}$ & $\begin{array}{c}76.7 \\
(86.6)\end{array}$ & $\begin{array}{c}76.8 \\
(86.5)\end{array}$ & $\begin{array}{c}76.7 \\
(87.0)\end{array}$ & $\begin{array}{c}68.3 \\
(83.1)\end{array}$ & $\begin{array}{c}65.3 \\
(79.6)\end{array}$ & $\begin{array}{c}51.8 \\
(64.2)\end{array}$ \\
\hline Turbot & & & \begin{tabular}{|c|}
85.4 \\
$(92.1)$
\end{tabular} & $\begin{array}{c}76.7 \\
(85.9)\end{array}$ & $\begin{array}{c}72.0 \\
(83.0)\end{array}$ & $\begin{array}{c}72.9 \\
(83.5)\end{array}$ & $\begin{array}{c}84.0 \\
(92.9)\end{array}$ & $\begin{array}{c}72.3 \\
(83.0)\end{array}$ & $72.0(83.7)$ & $\begin{array}{c}67.7 \\
(83.0)\end{array}$ & $\begin{array}{c}63.1 \\
(79.0)\end{array}$ & $\begin{array}{c}58.0 \\
(63.0)\end{array}$ \\
\hline Cobia & & & & $\begin{array}{c}79.6 \\
(87.5)\end{array}$ & $\begin{array}{c}75.6 \\
(85.9)\end{array}$ & $\begin{array}{c}76.7 \\
(86.8)\end{array}$ & $\begin{array}{c}75.8 \\
(85.5)\end{array}$ & $\begin{array}{c}75.9 \\
(85.6)\end{array}$ & $\begin{array}{c}75.8 \\
(85.8)\end{array}$ & $\begin{array}{c}70.8 \\
(84.5)\end{array}$ & $\begin{array}{c}65.8 \\
(84.5)\end{array}$ & $\begin{array}{c}51.8 \\
(65.1)\end{array}$ \\
\hline Atlantic Cod & & & & & $\begin{array}{c}76.7 \\
(86.6)\end{array}$ & $\begin{array}{c}76.0 \\
(85.5)\end{array}$ & $\begin{array}{c}75.7 \\
(85.1)\end{array}$ & $\begin{array}{c}72.7 \\
(86.9)\end{array}$ & $\begin{array}{c}77.3 \\
(86.8)\end{array}$ & $\begin{array}{c}70.7 \\
(83.0)\end{array}$ & $\begin{array}{c}64.6 \\
(79.7)\end{array}$ & $\begin{array}{c}50.9 \\
(79.7) \\
\end{array}$ \\
\hline Rainbow trout D6D & & & & & & $\begin{array}{c}92.3 \\
(95.8)\end{array}$ & $\begin{array}{c}95.5 \\
(96.5)\end{array}$ & $\begin{array}{c}98.2 \\
(98.5)\end{array}$ & $84.5(97.6)$ & $\begin{array}{c}66.1 \\
(81.7)\end{array}$ & $\begin{array}{c}65.0 \\
(79.5)\end{array}$ & $\begin{array}{c}53.6 \\
(67.5)\end{array}$ \\
\hline $\begin{array}{r}\text { Atlantic Salmon } \\
\text { D5D } \\
\end{array}$ & & & & & & & $\begin{array}{c}91.2 \\
(94.5) \\
\end{array}$ & $\begin{array}{c}92.1 \\
(94.9) \\
\end{array}$ & $95.2(96.9)$ & $\begin{array}{c}64.8 \\
(81.1) \\
\end{array}$ & $\begin{array}{c}63.9 \\
(79.3) \\
\end{array}$ & $\begin{array}{c}53.9 \\
(79.3) \\
\end{array}$ \\
\hline Atlantic salmon D6D & & & & & & & & $\begin{array}{c}94.3 \\
(95.8)\end{array}$ & $91.4(95.2)$ & $\begin{array}{c}65.4 \\
(80.4)\end{array}$ & $\begin{array}{c}65.0 \\
(79.7)\end{array}$ & $\begin{array}{c}54.2 \\
(66.7)\end{array}$ \\
\hline Cherry salmon D5D & & & & & & & & & $\begin{array}{c}94.3 \\
(96.9)\end{array}$ & $\begin{array}{c}66.4 \\
(81.6)\end{array}$ & $\begin{array}{c}65.3 \\
(79.2)\end{array}$ & $\begin{array}{c}52.5 \\
(65.7)\end{array}$ \\
\hline $\begin{array}{c}\text { Cherry salmon } \\
\text { D6D }\end{array}$ & & & & & & & & & & $\begin{array}{c}65.6 \\
(81.5)\end{array}$ & $\begin{array}{c}63.4 \\
(79.1)\end{array}$ & $\begin{array}{c}52.8 \\
(66.9)\end{array}$ \\
\hline Zebrafish D5D/D6D & & & & & & & & & & & $\begin{array}{c}64.9 \\
(79.3)\end{array}$ & $\begin{array}{c}50.7 \\
(66.1)\end{array}$ \\
\hline Human D6D & & & & & & & & & & & & $\begin{array}{c}55.5 \\
(67.5)\end{array}$ \\
\hline
\end{tabular}


Supplementary data 3. GC analysis of FAME from yeast transformed with the pYES2 empty plasmid (A, B) or pYES-D6D plasmid (C, D, E) and incubated in the presence of 0.5 mM 18:3n-3 (A, D); $0.5 \mathrm{mM}$ 18:2n-6 (B, E) and $1 \mathrm{mM} \mathrm{20:4n-3} \mathrm{(C).} \mathrm{Peaks} \mathrm{1,} \mathrm{2,}$ 3 , and 4 correspond to the four endogenous FA in Saccharomyces cerevisiae (16:0, 16:1n-7, 18:0 and 18:1n-9, respectively). The exogenously added FA substrates are represented by peaks 5 (18:3n-3), 6 (18:2n-6) and 7 (20:4n-3); peaks 8 and 9 account for 18:4n-3 and 18:3n-6 respectively, which were identified as the desaturated products produced in presence of 18:3n-3 and 18:2n-6. Each feeding experiment was performed in triplicate, and results of a representative experiment are shown.

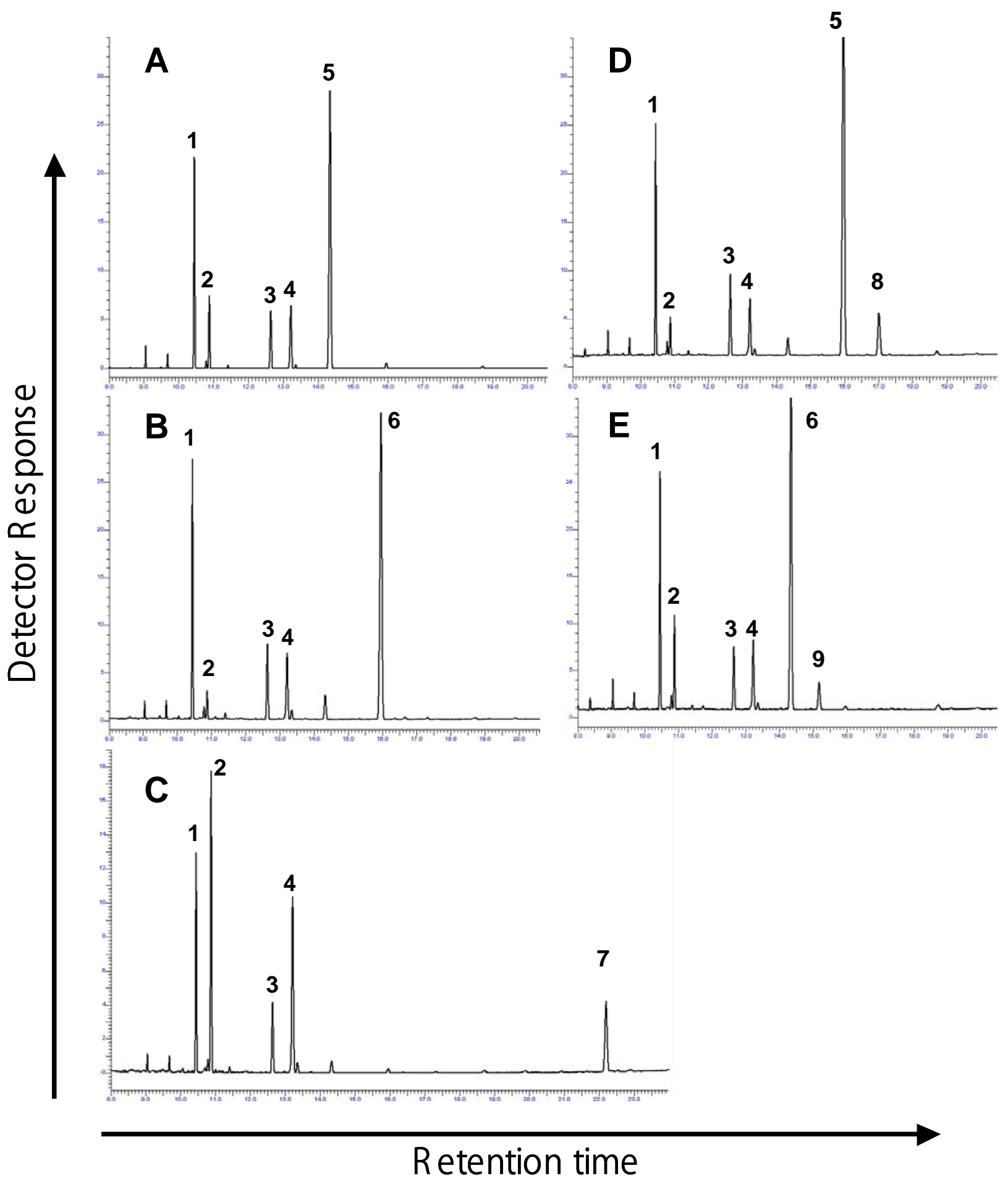

